\title{
ON AN IMPROVED SPRING AND AXLE BOX FOR RAILWAY CARRIAGES.
}

In springs serving as an elastic support various qualities are required for the different purposes. First, they must yield through a sufficient space, to absorb the momentum so gradually as to pre. vent shocks from being felt, and the space must be proportioned to the shock. Secondly, they should work with the minimum of friction between their parts. Thirdly, if used for varying loads, they should possess the property of equal yield under the light and the heary load ; an empty waggon should be as easy to ride in as a loaded one.

For springs required to moderate the shocks of buffing and traction in railway trains, a certain amount of friction in the springs is a positive advantage; it increases the temporary resistance, that is, adds to the strength of the spring, and also moderates the force of the recoil. But for bearing springs, quick action as well as range of movement is essential, and the quicker the speed of the train, the more important it becomes that the action should be rapid.

There are many modes of using steel in carriage springs; the simplest is the double lever form. In this form of spring the width of plate is limited only by convenience; the thickness must be limited by the power of equal hardening and tempering in the first place, and next by the convenience of length; up to a certain point the thickness of the steel may be increased with the length, and the power will be increased, but the yield through space may be made as great with a short thin spring as with a long thick one, though with lessened power. As the power is limited by the limit of the thickness of the plates, lamination or the multiplication of plates one on the other becomes necessary, and this is the commonest form of spring. Whether in single or multiplied plates, it is a direct action spring.

Indirect action springs exist of various kinds, in which the space or yield of the steel is multiplied by leverage other than that of the steel. The bow spring is one example, in which the pressure on 
the ends of a slightly arching bow is multiplied three times by levers. This is the most highly elastic spring known, the friction being confined to axis movements, but the cost of the framework of levers is greater than that of the steel.

For the purpose of simple arrangement the laminated lever spring offers the greatest advantages. It is an elastic lever if rightly formed. As a bearing spring it supports the framework of the carriage at different points. As a buffing spring it affords a facility for swivelling on the centre to adjust an equal pressure on the buffer heads, whether on curves or on straight lines of way. But the form and make of the spring may vary, and the elasticity may be impeded, or developed at the wrong part; and in the case of bearing springs the action may be rery hard with a light load, while the heavy load tends to break the spring.

The ordinary form of laminated spring, as in Figs. 1 and 2, Plate 30, is a curved line of greater or less radius; in some the curvature has been so great that the bearing points are almost rigid struts, and the steel will scarcely spring at all, and if loaded sufficiently the spring will bend or break over the axle box at the centre.

A form of spring like Eig. 3 has been used formerly, the shape of which is a double inflected curve. The tendency of this form is to a double action in curvature, and breakage where the curvature changes, and a liability when overloaded to set, as in Fig. 4.

The object to be aimed at is to make the spring so strong over the butt or centre that it cannot yield there, and to make the form such as to ensure its yielding sufficiently with a light load, and with an increasing capacity for supporting the load when it is heavy.

In the improved spring, the subject of the present paper, which the writer has adopted for this object, the plates are made in an angle shape, as shown in Figs. 5 to 9 , Plate 30 , and the specimens exhibited, being formed in two straight or nearly straight lines, rising from the centre, instead of the usual-curve. The spring is therefore very firm at the centre in the direction of the strain, whilst the taper points on the contrary are disposed to yield equally and easily, forming as they descend two gradually increasing curves, as shown in Fig. 6, diminish. ing the actual span of the spring, and consequently diminishing the leverage and increasing the pover of resistance. 
In the construction of the ordinary laminated springs with flat or slightly curved centres, it is necessary to resort to some method of keeping the several plates central and parallel. This is done either by a bolt passing through the whole of the plates in the centre, or by forming them with a series of studs by indenting the plates at the centre, and clipping the whole together. Either method tends to weaken the plates at the centre, and to break them if the fastenings get loose. To keep the plates parallel, the ends are indented to form studs which work in elongated slots in the plate below, as shown in the plan, Fig. 2, one plate keeping another parallel. But in the mode of ordinary work, these are very inefficient, and if the plates are not well fitted they work askew.

In the improved spring the centres of the plates are all creased to exactly the same angle, as shown in Fig. 7, and thus lie one within another without any tendency to curve lengthwise, each one lying in the valley below it. A clip, or a pair of coupling plates with bolts outside, shown in section in Fig. 8 , holds all the plates together, and the angle form retains them so firmly that all slots and studs at the extremities of the plates can be dispensed with.

In the ordinary spring the ends of the plates are tapered, as in the plan, Fig. 2. Originally they were tapered in thickness, but the late Mr. Chapman tried, and successfully, the experiment of tapering in width for private carriages. The length of taper he used was four times the width of the plates. When introduced on railways the desire to save steel gradually reduced the taper to one width, and sometimes to half a width. It has even been proposed to carry the saving of steel to the uttermost, by cutting one plate out of the cther with a one-sided taper; but the writer is not aware that this plan was ever adopted, and it is evident that it would tend to push the plates sideways.

In experimenting with the improved spring, the writer found that tapering in thickness caused considerable friction between the plates, by the ends binding against the hollows of the curves, and the tapering in width caused an irregular action. The method was therefore tried of simply cutting the plates off square, as shown in the plan, Fig. 9, slightly rounding the upper edge. This was found to give the most perfect elastic action, and without any waste of stecl. 
In making ordinary springs it tis customary to make the top or back plate of a given curvature, and to increase the curvature of every succeeding plate, afterwards compressing the whole together and fastening by the central bolt or elip. This plan renders the springs uncertain as to strength, and the hammering or setting, denting the surface of the plates, is very apt to cause fractures.

In the improved springs the plates are all creased to the same angle by a pressing machine, and any plate will fit any other plate without any setting up. They can therefore be kept in duplicate, and in case of breakage a common labourer can apply a new plate, without needing a smith and spring fire. Thus the improved spring wastes no steel, has no holes, no slots or studs, and no taper; it is nearly machinemade, and therefore more skilful workmen can be afforded for hardening and tempering; no files or expensive tools are required; and extra plates may be applied for greater loads by merely lengthening the bolts at the centre, and the springs may be made either with rolled eyes or plain ends as usual.

The action of this spring may be reversed, as shown in Figs. 10 and 11 , by placing the short plates in the bollow side, suspending the ends, and carrying the load in the centre.

The central angle may be either a sharp angle or a slight curve, but the sharp angle is preferable. If the curve be used more care will be required in fitting, as it is evident that the sharp angle will, in case of slight inaccuracy, hold the plates firmest : any angle may be used which will keep the plates central by the pressure without studs or bolts.

The springs are applied in the axle boxes so that the hoop or clip lies in a hollow, as shown in Fig. 12, Plate 31 , and no other fastening is required. This is very important, as, when the axle box is bolted to the spring, it is by inaccuracy frequently strained from its proper bed on the journal, and heating ensues, and continues till the bearing is worn down to a fit.

The axle box preferred by the writer is shown in Figs. 12 to 15 , Plate 31 , and the sample exhibited. It is a single casting $A$, with a thick wooden bottom $B$ which is bolted in when placed on the journal. There is a grease or oil chamber $\mathrm{C}$ with feed-holes above the journal, communicating by a large opening $\mathrm{D}$, at the front of the axle box, with 
the grease or oil chamber below. The box is rendered tight so as to contain a well of oil or grease, by two half cast metal collars $E$ at the back, the upper une supporting a spring that draws up the lower to clip the axle, which is formed to a conical shape at the back of the shoulder, so that the pressure of the spring always forces the collar down the cone and against the back of the box, but with a facility for a slight elastic yielding in case of any irregular resistance. It is obvious that as the collar slides up the cone, there will be a slight inaccuracy in the fit, but the wear will take place at the joint, where it is not important, and the lower half collar up to a sufficient height will always press close to the axle. In front of the box, and passing down the opening $\mathrm{D}$ inside, is a gun-metal slide $\mathrm{F}$, adapted for four changes, against which the end of the journal works, so that there is no need for any fit against the shoulder and collar, and the end wear of the brass is entirely prevented.

This box accordingly fulfils the several conditions required; namely, keeping the lower part of the axle in a bath of grease; saring the grease from waste; saving end wear of the brasses and oscillation of the carriage; diminishing the risk of heating by efficient ventilation; saving breakage of bottom castings; in case of heating, affording the facility of filling the box with water from above; saving the need of lifting the boxes, by allowing access below; and by reason of the absence of fastening, and the elasticity of the spring under all circumstances, diminishing the chance of heating.

The improved springs have been in use on the South Western Railway nearly six months, from the 5th of May last, and they have given every satisfaction. From an experiment made upon four springs on September 25 th, it was found that two of them, after a pressure of 3 tons had been applied, set $\frac{1}{8}$ th of an inch, and the other two resumed their original shape. The experiment was made after they had been in use upwards of four months, and had run a distance of 2434 miles under a heavy covered goods waggon; and previous to this working, they were also tested with the same weights without the least set being produced.

In point of first cost they are cheaper than the ordinary spring, inasmuch as a saving of $40 \mathrm{lbs}$. weight per set of four springs is 
effected, for a spring with 8 plates on the new plan is quite equal to a spring with"10 plates of the usual construction, the weight being 72 to $73 \mathrm{lbs}$. in the new, as against $81 \mathrm{lbs}$. in the old. The new springs are not so susceptible of derangement as the ordinary spring, and are more elastic and adapt themselves better to the loads; they are also less liable to break, and altogether form a simple and compact arrangement.

Mr. Apams exhibited several specimens of the improved spring, one of which was taken to pieces, and put together again; and also a specimen of the axle-box.

The Chatruar observed that the liability of the ordinary springs to a permanent set after wear was a greatobjection to them, and the comparative freedom from set of the new springs was an important consideration; also the simplicity of their form and make would be a practical recommendation. He enquired how long the new springs had been at work.

Mr. Adams replied that they had been at work nearly six months; the great advantage in the improved spring was the ease with which repairs could be effected, consequent upon the simplicity of its construction. No smithing was required, and the plates were heated only once, and creased and tempered at the same time, without requiring a second heating, the only process in making the spring that involved any skill or experience being the tempering of the plates. There was no danger of any lateral displacement of the plates, although they were not provided with studs and slots, the clip and the angle to which they were creased holding them securely against any derangement.

Mr. Ramsвoтtom remarked that in the ordinary spring the steel was weakened at the centre by the central bolt hole, which was a defect; and the new spring was superior in having no central bolt hole. He enquired whether any of the plates had been found to break across the centre, in consequence of the creasing.

Mr. ADAms answered that no damage had been found at present to be caused by the creasing, but the plates might no doubt be injured 
if creased too much, so as to crush the metal. In the ordinary spring a greater number of plates were required at the centre to make up for the loss of strength caused by the bolt hole; this added to the weight, and in the new spring, by avoiding the necessity for adding more plates, a saving of more than 40 lbs. per waggon was effected.

Mr. RAMSвоттом remarked that it was important in any laminated spring that under a great weight all the plates should be brought into full action throughout their entire length, and this appeared to be effected in the new spring. He enquired whether the action of the shortening leverage was fully realised in practice.

Mr. ADAms replied that he had not yet had an opportunity of making practical trial of the best form of the new spring, in which the ends shortened the leverage under a heary load by gradually curving down; the springs that had at present been tried, had been applied to waggons fitted with scroll irons, and consequently the springs had rolled ends. The shortening leverage would have the effect of increasing the rate of increase of the resistance, as the spring bent. The inverted form of spring that had been described was a convenient arrangement for the back end of a locomotive, where it was sometimes desired to substitute a single transverse spring or a pair for the two trailing springs ordinarily used, on account of the confined space available; in such a case, the above form of spring, requiring but little room for its action, and lying nearly straight between its two extremities, would be particularly eligible for the purpose. The construction of the new spring, in any of its forms, would readily allow of additional plates being inserted, so that its strength could be increased to suit any load it might be required to carry.

The Chatruas observed that vulcanized india-rubber springs had been frequently used for the trailing springs of engines, on account of the small space they occupied, and he enquired what results had been obtained from their working.

Mr. Ramsвotrom said that he had not tried them for all the springs of an engine, but he found them to answer very satisfactorily 
for the trailing wheels; it was important, however, that the indiarubber should not be overloaded.

Mr. ADams said that in order to ensure their proper performance, a large quantity of india-rubber must always be employed, and it was then too expensive a material to be much used. The cost of the tackle or attachments also, in the india-rubber springs, was greater than in the case of steel springs, and he thought steel was in the end the cheapest and most eligible material for bearing springs.

The Cifairman remarked that it had been supposed at one time that india rubber was perfectly elastic; but though highly so, it undoubtedly had its limits, and became rigid if over-strained; some of the india-rubber springs appeared to have failed from that cause.

Mr. ADAMs observed that in steel springs his experience had led him to the conclusion, that in whatever form the steel were disposed, whether the spring were a volute, spiral, flat, disc, bow, or laminated lever, there was always nearly the same quantity of steel required to give the same elastic action under the same load, supposing each to be the best form of its class; if the quantity of steel, and consequently the number of particles to bear the strain, were reduced, the action on each particle would be more severe, and the spring would become liable to set or break.

Mr. Ramsвotrom observed that he had been led also to a somewhat similar conclusion as to the weight of steel required being nearly the same for the same work, in whatever form it were arranged.

The Chatrman remarked that in the Report of the Commissioners on Railway Structures, an account was given of experiments made by Capt. James at Portsmouth Dockyard, on the effects of long repeated deflections upon the permanent elasticity of bodies; in some cases the repetitions of strain were carried up as high as 250,000 actions, and it was found that every material, however elastic, became finally deteriorated and failed, differing only in the extent and time of action.

Mr. Adams observed that the dise spring had been tried under a continuous deflection involving reaction, and it was found that it -would never serve for more than four hours' work before it 
broke; the effect of the continued action appeared to be the same as in the spring-beam helves used by steel makers for the tilt hammer's; these could not be worked more than four or five hours at a time, and then required six or eight hours' rest before they could be put to work again, when they appeared to have recovered their elasticity.

The Chairman said that the simple construction of the new spring that had been described, and its comparative cheapness, consequent upon the diminished weight and the ease with which it could be manufactured, were strong recommendations in its favour.

He proposed a vote of thanks to Mr. Adams for his paper, which was passed.

The following paper, by Mr. David Joy, of Worcester, was then read :- 
Fig.1. Ardinary Bearing Spring.

Fig. 2. Plan.
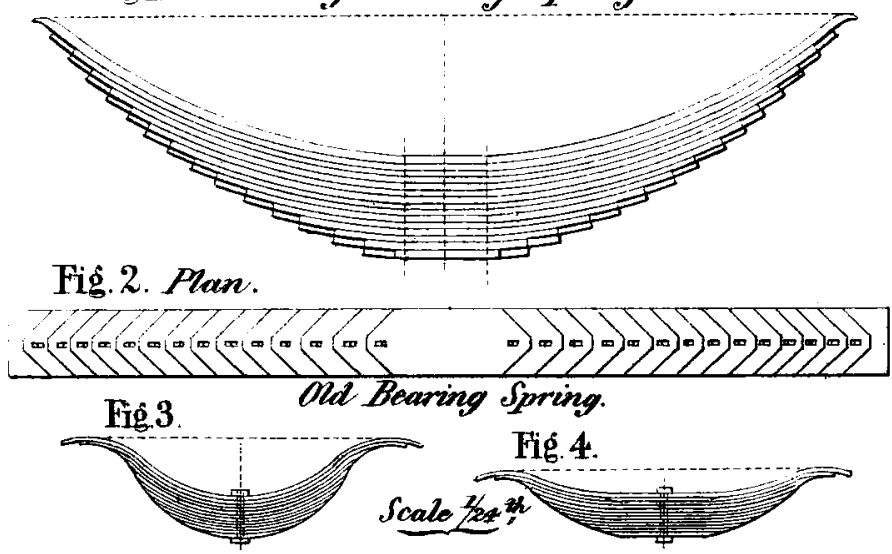

Fig.5.

Improved Bearing Spring

Fig.6.
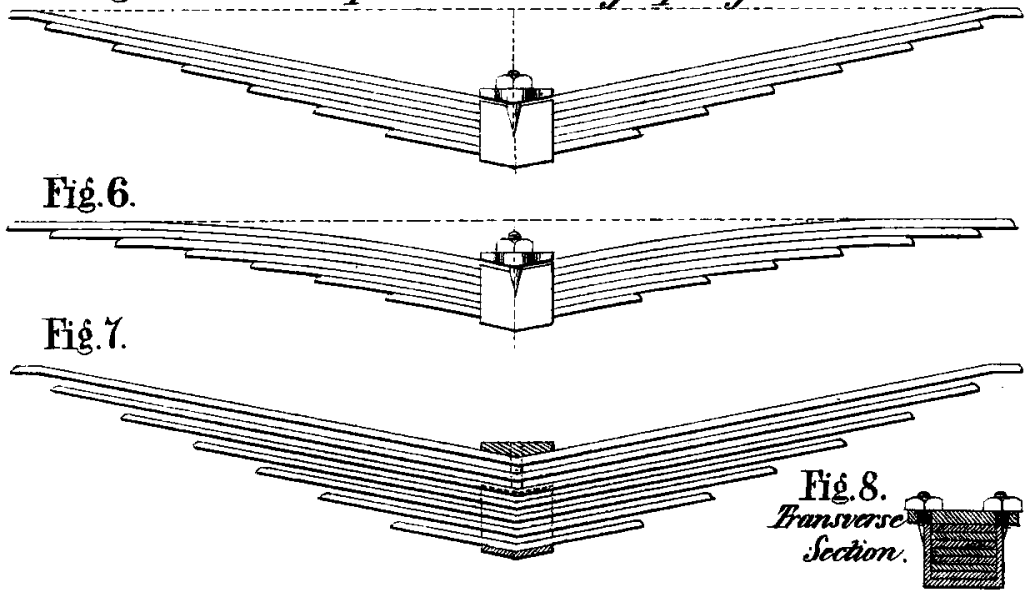

Fig.9. Plan.

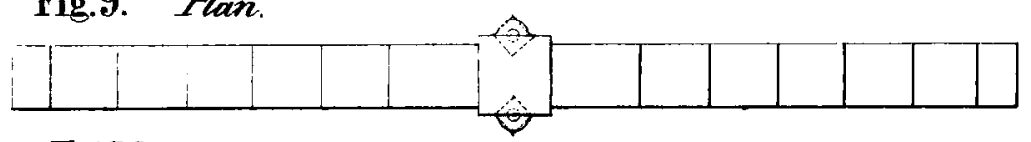

Fig.10.

Q

Fig.ll.

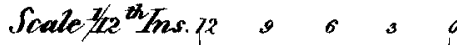




\section{RAILWAY AXLEBOX.}

Prate âs.

Fig. 12 .

Hransverse Section of Axlebax.

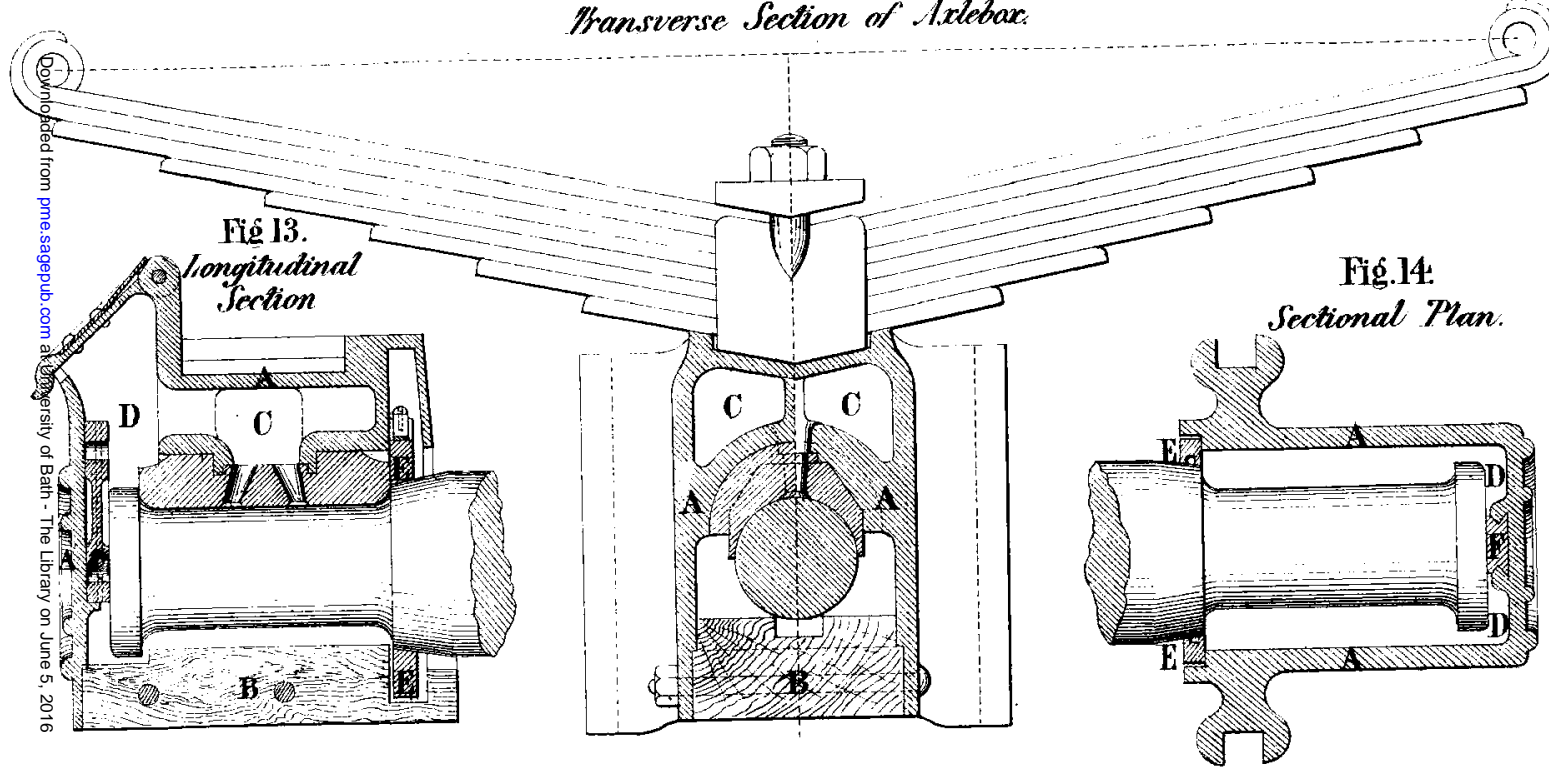

Fì. 15.

Bleurtion at Back

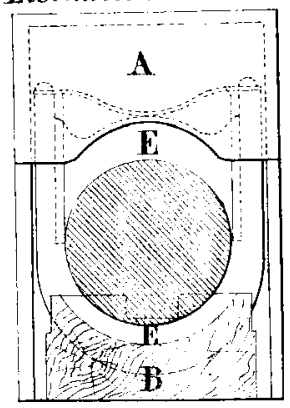

Sirale $\%$

20. Inches:

(Proneedings Inst M.L' 1855 Page 166.) 